\title{
Educational Reform of Teacher Based on the Flipped Classroom Teaching Model
}

\author{
Jing Duan \\ Hunan International Business Vocational College, Changsha, 410000, China
}

Keywords: Flipped classroom, Teaching model, Teacher education, Reform

\begin{abstract}
As a new teaching model, the flipped classroom provides a better educational platform and learning platform for teachers and students, and under the continuous development of information technology, the flipped classroom teaching model has become an important direction for future educational reform. Based on this, it discusses the reform of teach education under the flipped classroom teaching mode in this paper.
\end{abstract}

\section{Introduction}

With the continuous development of big data, mobile terminal, microblog and cloud technology, the society has entered into a time of diversified development. In this environment, people's teaching method and teaching philosophy have undergone tremendous changes. Flipped classroom teaching model is generated under this background, and has become a very hot topic in the current educational circles. Some schools in the developed countries have introduced the flipped classroom teaching model into the classroom, and have achieved good teaching results ${ }^{[1]}$. At present, China is still in the exploratory stage, and if it wants to introduce the flipped classroom teaching into the classroom, it needs to find a method of reform in line with China's national conditions.

\section{Challenges and Current Situation of China's Education}

In the new curriculum reform, it is clearly that the teaching should fully stimulates the thirst for knowledge and curiosity of students, protects students' self-esteem, cultivates students' interests and hobbies, creates a learning environment of free exploration and independent thinking, which require to combine the practical teaching with theoretical teaching, and to improve students' ability to solve problems. So far, China's curriculum reform has more than ten years' history, and has made remarkable achievements, but still has come problems.

Still Use the Inculcating Teaching Model

In the teaching process, the teaching models in many schools still adopt the inculcating teaching model, and the teacher is still the center of the classroom. In the examination-oriented education environment, the student in the classroom is still passively involved in the teaching.

\section{Low Comprehensive Quality of Students}

Because many teachers evaluate the quality of a student according to the academic records of the student, so although the level of students' intelligence has been improved, the development of society not just needs the students who can only study mechanically. The comprehensive quality of students is generally not high.

\section{Heavy Pressure and Burden of Students}

Under the guidance of the new curriculum reform, many primary and secondary schools have increased the corresponding practical classrooms, and relatively speaking, the learning time for theoretical knowledge is correspondingly reduced, so in order to compensate the occupied time and to improve the ability for the students to learn knowledge, many teachers will assign a lot of homework after school. And in order to improve children's academic records, some parents of students will let the students participate into various types of training courses in holidays, potentially increasing the pressure on our students. 


\section{Introduction of Flipped Classroom Teaching Model}

\section{Concept of Flipped Classroom}

There are many concepts about the flipped classroom teaching model, although the conceptual understandings of flipped classroom are different, the meanings they expressed are similar, which have rearranged the teaching processes. In general, the flopped classroom teaching is divided into the following steps:

1). The teacher needs to record the curriculum content taught in the classroom as teaching videos.

2) Share the prepared videos to the students, and allow the students to use their spare time to study independently.

3). After the completion of independent study, the students will conduct self-test about their learning conditions.

4). For the problems encountered during the process of training, the teacher gives guidance and help to the students for their independent studies. For some difficult problems, the students can do the study notes, and ask question to the teacher in the classroom, so the teacher will answer questions.

5). According to students' questions, the teacher will solve specifically and give enough time for students to understand.

6). The students are grouped and arranged grouping tasks. Each group will arrange a representative to demonstrate in the classroom, and other groups will evaluate the demonstration results, then the teacher will explain specifically according to the students' problems.

7). Upload some typical questions to the campus network, so the students do not have a thorough understanding of the problem can have a further consolidation and review about the knowledge.

\section{Advantages of the Flipped Classroom}

The flipped classroom insists on taking the students as the teaching subject, and taking the personality development of students as the key teaching points. The students can choose the knowledge they can understand to learn according to their own intellectual and cultural level, and make arrangements for their own learning process. Competent students also can conduct the expansion of knowledge, so that to avoid the excessive dependence of thinking and the mandatory of learning content in the traditional teaching process. The students are not only for learning the knowledge, but also for mastering the learning methods and having the learning ability for self-improvement.

As a test platform of knowledge and learning achievements, the classroom can further improve the communication and interaction between teachers and students by reducing the step of teaching knowledge, providing sufficient time for collaborative learning, and through the competition between students, it can improve students' expression skills, cultivate the spirit of students and develop their personalities. In addition, the flipped classroom provides a personalized learning platform for the teacher. Due to the existence of the big difference between teachers in personality, interest, skill and knowledge structure, so in the flipped classroom teaching model, the teacher can choose their own teaching ideas according to their own teaching characteristics, so that to create a personalized teaching style to fully reflect their own charisma. In order to improve the learning quality of students after class, in addition to arrange homework and ask questions to students, the teacher can use the software platform to track and record students' learning situations, and when teaching, the teacher can analyze students' learning schedule and learning effects according to the record, so that to design a teaching plan more in line with students' conditions. In the classroom, the teacher can accurately determine students' mastery of knowledge and determine whether they have encountered difficulties in learning, so that to give guidance specifically, to encourage students to innovate, and to enable students to become the subject of teaching. 


\section{Problems Encountered When China Introducing the Flipped Classroom Teaching Model}

\section{The Influence of Traditional Education Concept is Relatively Large}

The teacher's teaching concept has a very large impact on the implementation of flipped classroom teaching model. At present, many teachers still adhere to the teaching concept which focuses on teachers, take the classroom and teaching materials as the key point, and use the inculcating teaching model for teaching. If the teacher is the teaching subject, it has certain difficulties for receiving the flipped classroom teaching model. In addition, in the educational process, under the influence of utilitarianism, it too much emphasizes on student enrollment rate, and in order to improve the school's reputation and get good students, it repeatedly pursues the enrollment rate. And in order to achieve good results, go to an ideal university and have a good future, the students think a great deal of the enrollment rate. This to some extent limits the promotion of flipped classroom model.

\section{Limited Class Size}

Due to China's large population and the relative lack of educational resources, so it has a certain degree of difficulty to teach in small classes in the short term. In the flipped classroom teaching model, dialogue between teachers and students is an important teaching form, but if the class size is relatively large, it will influence the students' classroom participation in the learning process. The protagonist of interaction is often the students with good communication skills and outgoing personalities, but for the students with poor academic records and introverted personalities, it is very hard to attract the teacher's attention, resulting in serious polarization ${ }^{[3]}$. In addition, due to the space for teacher is relatively small, and the seats for students are generally fixed, so it is relatively difficult for the teacher to organize some diversified teaching interactions, which potentially restricts the communication frequency between teachers and students, so that the deep interaction required for the flipped classroom teaching model can not be reached.

\section{Students' Self-learning Ability is Poor}

The flipped classroom teaching model emphasizes that the students conduct independent study after class, and the teacher only plays a supporting role to provide students with the appropriate multimedia teaching resources. Students achieve self-learning by watching teaching videos, consulting learning materials and searching information online, test the effect of their own learning, summarize the knowledge they learnt, and solve the problems encountered in the learning process. These learning activities have higher requirements for the information literacy of learning and students' self-learning ability. Most of the students have accustomed to the supervision and guidance of teachers and parents in the learning process. If allows the students to study independently, there are some difficulties, which requires students to have goods skills of self-control and self-management. Due to the network is full of seductive stuffs, which will cause a great disturbance towards the learning of students, so if the students are lack of self-control, it is easy to get lost, which not only can not achieve the purpose of teaching, but also may affect the academic records of students. Therefore, the promotion of flipped classroom teaching model should firstly improve students' awareness of self-learning, cultivate students' ability of self-learning, and allow the students to develop good learning habits.

\section{The Relative Lack of Support of Information Technology}

The launch of flipped classroom teaching model is inseparable from the support of information technology. No matter the teacher makes teaching videos, or the students watch videos, is inseparable from the support of hardware and software. In the process of students' self-learning, to ensure the students will not be restricted by the geographical network, it should has abundant learning resources, which can be shared at the greatest extent on a global scale ${ }^{[4]}$. Because China is still a developing country, many students' families have not yet installed computers to watch the learning resources made by the teacher, so it has limited the self-studying of students after class. In addition, many teachers are not skilled in using the teaching hardware and software, so they can not take advantages of information technology to create a good learning environment, let alone to make some high-quality learning resources. 


\section{Lack of Perfect Evaluation Criteria}

Education is not accomplished in an action, but a process of long-term accumulation. At present, when evaluating the learning of students, our country mainly evaluates the teaching achievement based on the academic records of students and enrollment rate, and the evaluation method is too simple. The evaluation methods and techniques do not be attached importance, which need to be further improved.

\section{Reform Measures of Teaching in the Flipped Classroom Teaching Model}

\section{Conduct Rational Reform Combined with China's Basic National Conditions}

At present, when implementing the flipped classroom teaching model, many schools in China blindly follow the trend, resulting in a waste of educational resources. Because the flipped classroom teaching model is introduced from abroad, it is not fully adapted to China's basic national conditions. Therefore, we need to find out the core of the flipped classroom teaching model according to the research situation of our first-line educational workers, and to explore the teaching philosophy behind this model, and develop a teaching model in line with China's national conditions according to China's actual situations ${ }^{[5]}$, so that to promote the comprehensive development of students' virtues, intellects and physical education in the true sense.

\section{Improve the Professional Levels of Teachers}

In the flipped classroom teaching model, the professional level of teachers has higher requirements. Whether it is possible to make full use of the flipped classroom teaching model, the teacher plays an important role. When carrying out the flipped classroom teaching model, the teacher needs to make classroom teaching videos, and the quality of videos directly affects the implementation effects. In actual teaching process, due to the teachers in many schools are old, it is difficult for them to make courseware, let alone to record videos. Due to these teachers are accustomed to the traditional teaching models, it is very difficult for them to accept new things. At this point, the teacher needs to work together with the school to make efforts and study constantly, providing training opportunities for the majority of teachers.

\section{Change the Traditional Teaching Concepts}

At present, in China's primary and secondary education, the traditional teaching philosophy is still deeply rooted, and the teacher is still the classroom's subject, who constantly teaches students the knowledge in the textbook, while the students constantly acquire the knowledge, accumulate the knowledge and store the knowledge. In the learning process, students are afraid to express their views and opinions, and are lack of innovations. Under the influence of this concept, students just blindly pursue the academic records and are lack of the ability to think independently. In this case, if we want to promote the flipped classroom teaching model, the teacher, schools and educational authorities are required to make changes in the traditional teaching philosophy, to establish new teaching viewpoints ${ }^{[6]}$, and to establish a "student-centered" teaching concept. Only establishing the correct teaching ideas can produce the correct teaching behaviors. The implementation of the flipped classroom teaching model needs to break the status of the original educational environment, and to re-establish a new equilibrium.

\section{Improve the Support of Information Software and Hardware}

In the flipped classroom teaching model, the information technology is a very important component, which directly has an impact on the learning depth and learning environment of students. Therefore, the school should be equipped with good hardware technology and equipment, and develop the learning materials in their spare time. Schools should organize trainings for teachers to learn how to record teaching videos and use campus platform, so that to improve the educational ability of teachers and IT operational capacity. Therefore, the teacher will teach students to learn the methods of information acquisition and information assessment, so that students can study independently with high efficiency without the help of the teacher. 


\section{Conclusion}

In summary, the traditional classroom teaching model is essentially different from the flipped classroom teaching model in nature, and not every subject can use the flipped classroom teaching model. Through practices, we find that the flipped classroom model is mainly applied to practical courses. In order to make the flipped classroom model be applied to more courses, it needs the majority of teachers to constantly innovate and improve, and to let every teacher and parent agree with the flipped classroom teaching model. At present, researches about the flipped classroom teaching are mainly stopped in the practical research stage, and can not fundamentally achieve the innovation of teaching. In order to make the flipped classroom teaching model can be better developed, it also needs students, parents and teachers to work together to make more efforts.

\section{Acknowledgments}

The project name: Research and Practice on the Space Teaching Model of Higher Vocational Education Based on the Cloud Platform of World University Town. Project Number: GZYZD1213004.

\section{References}

[1] Zhang Yujiang. "Flipped Classroom Reform”. China Information Technology Education, 2012, (03): 70-73.

[2] Zhang Yueguo, Zhang Yujiang. Analysis on "Flipped Classroom”. IT Education in Primary and Secondary Schools, 2012, (03):83-86.

[3] Zhang Jinlei, Wang Ying, Zhang Baohui. Introducing a New Teaching Model: Flipped Classroom. Distance Education Journal, 2012, (02): 94-97.

[4] Guan Zhongke. What Has Been Reversed In the Reversed Classroom Zone. China Information Technology Education, 2012, (05): 69-74.

[5] Jiang Jianhua. Classroom Teaching Attempts Integrated with the Life Experience. Journal of Inner Mongolia Normal University (Education Science Edition), 2013, (10): 1-3.

[6] Jin Ling. What Has Been Flipped In the "Flipped Classroom”. China Information Technology Education, 2012, (09): 38-43. 